\title{
CULTURA POLÍTICA GERMÂNICA, RELAÇÕES DE FORÇA E RECEPÇÃO NO BRASIL A PARTIR DO PENSAMENTO DE RUDOLF VON JHERING, ERNST HAECKEL E HANS KELSEN (1879-1939)
}

\author{
CULTURA POLÍTICA GERMÁNICA, RELACIONES DE FUERZA Y \\ RECEPCIÓN EN BRASIL A PARTIR DEL PENSAMIENTO DE RUDOLF VON JHERING, \\ ERNST HAECKEL Y HANS KELSEN (1879-1939)
}

\section{GERMANIC POLITICAL CULTURE, POWER RELATIONS AND RECEPTION IN BRAZIL ACCORDING TO RUDOLF VON JHERING, ERNST HAECKEL Y HANS KELSEN (1879-1939)}

\section{CULTURE POLITIQUE GERMANIQUE, RAPPORTS DE FORCES ET RÉCEPTION AU BRÉSIL À PARTIR DE LA PENSÉE DE RUDOLF VON JHERING, ERNST HAECKEL ET HANS KELSEN (1879-1939)}

\section{DOI: $\underline{10.5533 / 1984-2503-20113303}$}

Ricardo Gaulia Borrmann

\section{RESUMO}

Este trabalho analisa a cultura política alemã em suas relações com a cultura política brasileira, desde um enfoque da história cultural (e das ideias), no período de 1879 a 1939. Analisamos os processos de circulação de ideias e apropriação cultural de três autores: Rudolf von Jhering, Ernst Haeckel e Hans Kelsen, pensadores relevantes para o campo jurídico germânico. A recepção no Brasil destes autores é verificada a partir dos intelectuais do campo jurídico no Brasil: Clóvis Bevilaqua e Silvio Romero, bem como das discussões em torno da Constituição brasileira de 1934. Trabalhamos as mediações culturais presentes nesse processo, entre elas a da cultura ibérica e a da francesa. Nossa hipótese é a de que, ao mesmo que tempo em que ocorre a recepção de autores germânicos, esse processo é mediado pela tradução e apropriação de múltiplas culturas políticas, sendo a ibérica e a francesa as mais evidentes. A pesquisa está fundamentada 
em acervos bibliográficos da Sessão de Obras Raras da Biblioteca Nacional do Rio de Janeiro e da Biblioteca do Tribunal de Justiça do Estado do Rio de Janeiro (TJRJ). O trabalho faz parte da pesquisa de doutorado em andamento.

Palavras-chave: cultura política, cultura jurídica, circulação de ideias e apropriação cultural, Brasil, Europa Germânica.

\section{RESUMEN}

Este trabajo analiza la cultura política alemana en sus relaciones con la cultura política brasileña, desde un enfoque de la historia cultural (y de las ideas), en el periodo de 1879 a 1939. Analizamos los procesos de circulación de ideas y de apropiación cultural de tres autores: Rudolf von Jhering, Ernst Haeckel y Hans Kelsen, pensadores relevantes para el campo jurídico germánico. La recepción de estos autores en Brasil es verificada a partir de los intelectuales del campo jurídico: Clóvis Bevilaqua y Silvio Romero, así como de las discusiones en torno a la Constitución brasileña de 1934. Trabajamos las mediaciones culturales presentes en ese proceso, entre ellas las de las culturas ibérica y francesa. Nuestra hipótesis es que, al mismo tiempo en que ocurre la recepción de autores germánicos, ese proceso es mediado por la traducción y apropiación de múltiples culturas políticas, siendo la ibérica y la francesa las más evidentes. La investigación está fundamentada en acervos bibliográficos de la Sesión de Obras Raras de la Biblioteca Nacional de Río de Janeiro (TJRJ). El trabajo forma parte de la investigación doctoral en marcha.

Palabras-clave: cultura política, cultura jurídica, circulación de ideas y apropiación cultural, Brasil, Europa Germánica.

\section{ABSTRACT}

This work analyses the relation between German and Brazilian political culture beginning with a focus on cultural history (and ideas) between 1879 and 1939. We analyze the circulation of ideas and the cultural appropriation of three authors on the German legal field: Rudolf von Jhering, Ernst Haeckel and Hans Kelsen. The reception of these authors 
in Brazil may be gleaned from works by writers on the legal field in Brazil: Clóvis Bevilaqua and Silvio Romero, and in the discussions on the Brazilian Constitution in 1934. We consider the cultural mediations present in this process, among them those of French and Iberian culture. Our hypothesis is that the process of these German authors' reception in Brazil was mediated by the translation and appropriation of multiple political cultures, with the French and Iberian the most evident. The survey is grounded in bibliographical collections from the Collection of Rare Works at the Rio de Janeiro National Library and the Superior Court of the State of Rio de Janeiro (TJRJ) Library. The article forms part of a doctorate in progress.

Keywords: political culture, judicial culture, idea circulation and cultural appropriation, Brazil, Germanic Europe.

\section{RÉSUMÉ}

Ce travail analyse du point de vue de l'histoire culturelle (et des idées) la culture politique allemande et ses relations avec la culture politique brésilienne entre 1879 et 1939. Nous analyserons les processus de circulation des idées et d'appropriation culturelle de trois auteurs important du champ juridique germanique : Rudolf von Jhering, Ernst Haeckel et Hans Kelsen. La réception de ces auteurs au Brésil peut être analysée à partir des travaux d'intellectuels du champ juridique brésilien, comme Clóvis Bevilaqua et Silvio Romero, mais aussi sur la base des débats autour de la Constitution brésilienne de 1934. Nous nous intéresserons aux médiations culturelles présentes dans ce processus, et en particulier à celles des cultures ibérique et française. Selon nous, ce processus de réception des auteurs germaniques se fait à travers le prisme de différentes cultures politiques, principalement ibérique et française. Cette recherche se base sur le fonds bibliographique de la Section des œuvres rares de la Bibliothèque nationale de Rio de Janeiro et de la Bibliothèque du Tribunal de justice de l'État de Rio de Janeiro (TJRJ). Ce travail fait partie d'une recherche doctorale en cours.

Mots-clés: culture politique; culture juridique; circulation des idées et appropriation culturelle ; Brésil ; Europe germanique. 


\section{Introdução}

Este trabalho tem por objetivo apresentar em linhas gerais algumas das questões propostas em nossa pesquisa de doutoramento, intitulado "Cultura Política Alemã, relações de força e sua recepção no Brasil, a partir do pensamento de Rudolf von Jhering, Ernst Haeckel e Hans Kelsen (1879-1938)"1. Faz parte, portanto, de um esforço para avançar nas pesquisas e aprofundar-se na temática. Pretendemos expor uma pequena parcela das pesquisas já realizadas para a elaboração da referida pesquisa, destacando seus aportes teóricos, suas hipóteses de trabalho e seus desdobramentos para a história política e para a cultura jurídica, temas presentes em Passagens. Revista Internacional de História Política e Cultura Jurídica.

O conjunto de questões desta pesquisa surgiu a partir das discussões conjuntas e dos trabalhos coletivos desenvolvidos no grupo multidisciplinar situado do Laboratório Cidade e Poder (LCP), vinculado ao Departamento de História e seu Programa de PósGraduação em História Social da Universidade Federal Fluminense (UFF) em Niterói, no Estado do Rio de Janeiro.

Esta pesquisa se relaciona diretamente com a temática da circularidade das ideias jurídicas entre Brasil e Europa no período de passagem à modernidade (fins do século XIX e primeiras décadas do XX) - mais especificamente entre Brasil e Alemanha e visa à análise das relações entre as ideias jurídicas e a cultura política. Estudamos estas questões dentro de uma perspectiva da história cultural (e das ideias), a partir de autores específicos de ambos os lados do Atlântico, todos de grande relevância para o campo jurídico, embora não restritos a este.

Seu escopo integra, portanto, o campo temático de vinculada ao Laboratório Cidade e Poder (LCP) e ao Departamento de História da UFF, dialogando ainda com o projeto de pesquisa dos professores Drs. Gisálio Cerqueira Filho e Gizlene Neder²,

\footnotetext{
${ }^{1}$ Este projeto foi apresentado a uma comissão mista de avaliadores ad hoc composta por membros da CAPES, do CNPq e do DAAD e agraciado com uma bolsa de doutoramento integral para a República Federal da Alemanha, cujos trabalhos se iniciarão em 1ํ de Abril de 2012.

${ }^{2}$ Os professores Dr. Gisálio Cerqueira Filho e Gizlene Neder integram o LCP e foram respectivamente orientador e co-orientadora da dissertação de mestrado do presente pesquisador, intitulada "Tal Mercado,
} 
intitulado "Duas Margens: Ideias Jurídicas entre Brasil e Portugal na Passagem à modernidade"3. É um trabalho que também possui vínculos internacionais. Assim, coaduna-se com o espírito de trocas (acadêmicas), que sempre pautaram a atuação do LCP. Refiro-me especialmente ao "Colóquio Internacional Sociabilidades, Poder e Cultura Política", que em 2011 teve sua 3a edição em uma parceria com o Instituto Superior de Ciências Sociais e Políticas da Universidade Técnica de Lisboa (UTL). Nesta ocasião tive a oportunidade de apresentar uma versão mais enxuta deste trabalho ${ }^{4}$.

Tal como as ideias e os intelectuais que aborda, atravessa também o Atlântico, passando pelo Departamento de História Cultural da Universidade Ludwig-Maximilian, de Munique, onde será orientado, em breve, pela professora Dra. Ursula Prutsch historiadora latino-americanista, especialista nas relações entre a Europa Germânica e o Brasil -, por intermédio de uma bolsa de doutoramento concedida pelo DAAD (Serviço de Intercâmbio Acadêmico Alemão) em parceria com a CAPES e o CNPq. Imprescindível neste processo de construção do escopo da pesquisa, além da atuação da Dra. Prutsch, foi a figura mediadora do professor Dr. Enrique-Rodrigues Moura, do Departamento de Romanística da Universidade de Göttingen; um estudioso das relações ibero-americanas e membro do Corpo Editorial desta Revista. Este trabalho se situa, pois, no vórtice desses três eixos situados nas cidades de Niterói, Munique e Göttingen.

\section{Circulação, recepção, tradução e apropriação cultural}

1. Muitos autores germânicos foram lidos e recepcionados no Brasil, especialmente em fins do século $\mathrm{XIX}^{5}$, contrariando as ideias corriqueiras de "atraso" ou

Tal Príncipe: o paradigma da perfeição na economia política burguesa”, defendida no Programa de PósGraduação em Teoria Política da UFF em 2009.

${ }^{3}$ Ver http://www.historia.uff.br/lcp/pesq.php

${ }^{4} \mathrm{O}$ Colóquio foi realizado nos dias 30 de junho e $1^{\circ}$ de julho na UFF em Niterói, no Estado do Rio de Janeiro. Agradeço as sugestões e comentários dos professores João Bilhim e Pedro Borges Graça, ambos do Instituto Superior de Ciências Sociais e Políticas da UTL, dos Professores Gisálio Cerqueira Filho e Gizlene Neder, sem os quais este trabalho não teria sido possível, e aos colegas pesquisadores presentes na ocasião.

${ }^{5}$ Neste particular ver FREYRE, Gilberto (s/ data, 2ª Ed.). 'Nós e a Europa Germânica' - Em torno de alguns aspectos das relações do Brasil com a cultura germânica no decorrer do século XIX, Rio de Janeiro: Editora Bra-Deutsch, p. 51. O historiador Antônio Carlos Villaça também chega a afirmar que a publicação dos "Estudos Alemães" de Tobias Barreto, em 1882, "abre o período de influência germânica na cultura 
de "ausência de modernidade". A Ibero-América (incluindo aí o Brasil) estava, na realidade, em contato com as diversas correntes do pensamento europeu, participando do amplo processo de circulação de ideias e apropriações culturais com a Europa ${ }^{7}$. Essas são algumas das teses que dão suporte às reflexões contidas neste trabalho.

Assim, as eventuais particularidades da recepção do pensamento alemão na Ibero-América são analisadas como fruto de uma cultura política singular e não como produto da falta de algo (modernidade, revolução, seja ela política ou industrial) ${ }^{8}$. Dentro do escopo teórico da história cultural, argumentamos, portanto, que o acesso a essa cultura política singular se dá através da análise dos processos de circulação e apropriação cultural de ideias e de livros ${ }^{9}$.

2. No Brasil as influências do pensamento germânico fizeram-se especialmente presentes na Faculdade de Direito do Recife ${ }^{10}$, chamada posteriormente, já no século $X X$, de "Escola do Recife"11. É o caso de intelectuais como Tobias Barreto - estudioso e entusiasta do pensamento germânico -, Clóvis Bevilaqua e Silvio Romero, todos oriundos da referida "Escola" e parte da geração de $1870^{12}$ no Brasil. Destacamos Clóvis Bevilaqua e Silvio Romero, que se mudaram para o Rio de Janeiro, à época a Capital Federal,

brasileira" (VILLAÇA, Antônio Carlos (1975). O Pensamento Católico no Brasil, Rio de Janeiro: Zahar Editores, p. 10.).

${ }^{6}$ Para uma crítica da ideias de atraso nas formações sociais portuguesa e brasileira ver NEDER, Gizlene (2000). Iluminismo Jurídico-Penal Luso-Brasileiro: obediência e submissão, Rio de Janeiro: Freitas Bastos, especialmente o capítulo II "Poder, Cultura e Ideias Jurídicas em Portugal - Séculos XVI e XVII", p. 33-100.

${ }^{7}$ Ver também NEDER, Gizlene e CERQUEIRA FILHO, Gisálio (2007). Ideias Jurídicas e Autoridade na Família, Rio de janeiro: Ed. REVAN.

${ }^{8}$ Sobre este particular a professora Dra. Gizlene Neder afirma: "(...) não devemos abraçar a ideia de que as formações sociais ibéricas são 'atrasadas', porque este encaminhamento inscreve-se num modo de ver as opções políticas pela falta (de modernidade, de revolução, etc.), produtora de uma situação de inferioridade em relação às formações sociais de além-Pirineus. Para esta perspectiva que enfatiza o atraso, Portugal, ao entrar na órbita de influência do capitalismo britânico, assinava seu destino de país não desenvolvido e periférico. No entanto, se olharmos a questão da 'escolha política' das elites, e suas implicações econômico-sociais, teremos outro enfoque." (NEDER, Gizlene (2000). Op. Cit., p. 36.)

${ }^{9}$ Ver NEDER, Gizlene e SILVA, Ana Paula Barcelos Ribeiro da (2009). "Intelectuais, Circulação de Ideias e Apropriação Cultural: Anotações para uma Discussão Metodológica". In Passagens. Revista Internacional de História Política e Cultura Jurídica, Rio de Janeiro: vol. 1 no. 1, janeiro/julho, p. 29-54. Ver ainda NEDER, Gizlene (2000). Op. Cit.

${ }^{10}$ FREYRE, Gilberto (s/ data, $2^{\text {a }}$ Ed.). Op. Cit.

${ }_{11}^{11}$ Ver PAIM, Antônio (1966). A Filosofia da Escola do Recife. Rio de Janeiro: Editora Saga.

${ }^{12}$ Para um estudo preocupado com a questão geracional e a sua relação com o contexto sócio-político da época, ver ALONSO, Ângela (2000). "Crítica e Contestação: o movimento reformista da geração de 1870". In Revista Brasileira de Ciências Sociais (RBCS), Vol. 15, no. 44, out., p. 35-55. 
provocando uma influência de corte nacional ${ }^{13}$, devido a sua atuação como intelectuais e a sua importância no pensamento social e político brasileiro. Clóvis Bevilaqua foi o redator do Código Civil Brasileiro, que entrou em vigor em 1916 e Silvio Romero membro do Instituto Histórico e Geográfico Brasileiro (IHGB), professor da Faculdade Livre de Ciências Jurídicas e Sociais do Rio de Janeiro (que entra em funcionamento apenas em 1891) e do Colégio Pedro II. Ambos são membros-fundadores da Academia Brasileira de Letras ( $A B L)$. Bevilaqua e Romero, por sua vez, (assim como Tobias Barreto) foram muito influenciados pelo jurista Rudolf von Jhering e pelo naturalista Ernst Haeckel, ambos pensadores alemães ${ }^{14}$.

Já no século $X X$, encontramos a presença marcante de outro jurista germânico, porém de origem austríaca, no Brasil: Trata-se de Hans Kelsen - um dos principais arquitetos da Constituição Austríaca de $1920^{15}$; e, particularmente importante nos debates em torno da Constituição brasileira de $1934^{16}$.

3. Apesar das fortes influências germânicas que sofreram determinados intelectuais, poucos destes efetivamente conheceram a Europa Germânica através de viagens. À escassez de viagens em comparações com destinos como Portugal ou França somam-se ainda as dificuldades apresentadas pelo idioma alemão. Daí a importância ampliada, no que tange o contato com a cultura germânica, dos livros, traduções e, certamente, do contato com imigrantes tudescos ${ }^{17}$.

\footnotetext{
${ }^{13}$ Ver NEDER, Gizlene (1995). “Juristas', 'Bacharéis' e a Ideia de Nação”. In Discurso Jurídico e Ordem Burguesa no Brasil, Porto Alegre: Sergio Antonio Fabris, p. 99-130.

${ }^{14}$ Sobre essas influências ver MORAES FILHO, Evaristo de (1979). "O pensamento Político-Social de Silvio Romero". In ROMERO, Silvio. Realidades e ilusões no Brasil: Parlamentarismo e presidencialismo e outros ensaios, Petrópolis: Vozes: Aracajú: Governo do Estado de Sergipe. Sobre a importância de Jhering para Bevilácqua, ver especialmente o prefácio deste para o livro JHERING, Rudolf von (1955). Questões e Estudos de Direito; Tradução de João Vieira de Araujo, Clóvis Bevilácqua, Adherbal de Carvalho, Bahia: Livraria Progresso.

${ }^{15}$ Ver FERRAZ JR., Tércio Sampaio (2000). "Por que ler Kelsen, Hoje”. In COELHO, Fábio Ulhoa. Para entender Kelsen, São Paulo: Max Limonad, p. 13-20.

16 Ver PRUTSCH, Ursula (1999). "Instrumentalisierung deutschsprachiger Wissenschafter zur Modernisierung Brasiliens in den dreißiger und vierziger Jahren". In Zeitgeschichte.at, Innsbruck: Studienverlag, p. 362-69.

${ }_{17}$ Para um estudo sobre a importância da atuação regional dos imigrantes tudescos, a partir do caso de um intelectual particular e dentro de uma perspectiva metodológica que se coaduna com a nossa, ver GRÜTZMANN, Imgart (2007). "Intelectuais de fala alemã no Brasil do século XIX: o caso de Karl von Koseritz (1830-1890)". In História Unisinos, Vol. 11, no. 1, Janeiro/Abril, p. 123-133.
} 
4. Assim, ao trabalharmos com a "a história das leituras" enquanto uma "prática cultural"18 $^{\text {,18 }}$ não se pode ignorar que estas mesmas leituras sofreram suas mediações, particularmente por intermédio das traduções. Neste particular, destacamos a influência que exerceu a cultura e as traduções francesas. Outro aspecto que se deve levar em conta são as relações de força (políticas) ${ }^{19}$, típicas dos processos de circularidade e apropriação de ideias no campo cultural. Tampouco se pode ignorar a influência de Portugal e da mediação da própria cultura ibérica. Esta é, em linhas gerais, a problemática desta pesquisa.

5. Tratamos, pois, menos dos autores em si e do conteúdo das suas doutrinas ou de seu pensamento e mais da recepção e circulação de suas ideias dentro de determinada conjuntura política determinada, com vistas a descortinar, compreender melhor um pequeno fragmento desta enorme complexidade que constitui uma "cultura política" particular.

\section{A temporalidade e suas pertinências}

O recorte temporal escolhido compreende o período que vai de 1879 a 1939.

Esse recorte se justifica, pois em 1879 ocorre a Reforma Leôncio de Carvalho, que institui o ensino livre no Brasil, ensejando a criação de outras instituições de ensino superior na área do direito neste país - o que só iria ocorrer efetivamente em 1891 com a criação da Faculdade Livre de Ciências Jurídicas e Sociais do Rio de Janeiro -, visto que, até então, as duas únicas Faculdades de Direito eram a de Recife (primeiro Olinda) e a do Largo do São Francisco, em São Paulo, ambas criadas por decreto imperial em 1827. A sua conseqüência direta foi não apenas a quebra do monopólio do ensino jurídico, mas

\footnotetext{
${ }^{18}$ Ver especialmente CHARTIER, Roger (org.) (1996). Práticas da Leitura, São Paulo: Estação Liberdade.

${ }^{19}$ Sobre as relações de força, destaco passagem do historiador Carlo Ginzburg: “(...) ao avaliar as provas, os historiadores deveriam recordar que todo o ponto de vista sobre a realidade, além de ser intrinsecamente seletivo e parcial, depende das relações de força que condicionam, por meio da possibilidade de acesso a documentos, a imagem total que uma sociedade deixa de si. Para 'escovar a história ao contrário' (die Geschichte gegen den Strich zu bürsten), como Walter Benjamin exortava a fazer, é preciso aprender a ler os testemunhos às avessas, contra as intenções de quem os produziu. Só dessa maneira será possível levar em conta tanto as relações de força quanto aquilo que é irredutível a elas." (GINZBURG, Carlo (2002). Relações de força: história, retórica, prova, São Paulo: Companhia das Letras, p. 43.)
} 
também das humanidades, uma vez que naquela época as Faculdades de Direito englobavam também o campo das humanidades ${ }^{20}$, inclusive a Filosofia e a Literatura.

Em 20 de janeiro de 1939 ocorre o fechamento definitivo do último bastião do ensino livre no Brasil, Universidade do Distrito Federal (UDF) ${ }^{21}$, com a sua incorporação pela Universidade do Brasil ${ }^{22}$, já no contexto da Reforma Educacional Francisco Campos, de 1931. Esta reforma ensejou a separação do ensino jurídico das humanidades, cuja conseqüência imediata foi um ensino mais tecnicista do direito.

Esse recorte se justifica, em primeiro lugar, pois compreende o período histórico de vigência da reforma educacional de 1879 - Leôncio de Carvalho -, no qual se difundiu o ensino livre no Brasil. Assim, está diretamente relacionado com o nosso objeto - a circularidade de ideias entre Brasil e Alemanha -, uma vez que o campo jurídico no Brasil se desenvolveu particularmente em torno das Faculdades de Direito. Trata-se, pois, de um período de descentralização do ensino jurídico e, por conseguinte das humanidades, no qual pretendemos investigar a circulação e recepção dos autores germânicos mencionados. Por fim, é uma temporalidade que se aproxima também de importantes marcos da história política alemã (Unificação em 1871, ascensão de Hitler ao poder em 1933 e início da Segunda Guerra Mundial em setembro de 1939).

Dentre os objetivos gerais deste trabalho distingo cinco principais; os três primeiros são de caráter mais geral e os dois últimos mais específicos. Todos, porém, estão inter-relacionados.

A.) Esperamos poder contribuir para um olhar diferenciado da cultura (política) alemã, a partir do rastreamento da inscrição de alguns intelectuais e suas ideias nesta cultura e de sua recepção no Brasil, analisando os processos de circulação das ideias. Assim, não desejamos reproduzir estereótipos e idealizações da cultura germânica, que, após as duas Grandes Guerras e o Nazismo ficou profundamente marcada pelo estigma

\footnotetext{
${ }^{20}$ Ver NEDER, Gizlene e CERQUEIRA Filho, Gisálio (2004). "A Teoria Política no Brasil \& o Brasil na Teoria Política". In 4ํㅡㄹ Encontro da Associação Brasileira de Ciência Política (ABCP), 21-24 de julho, PUC-RJ, p. 4. Ver também NEDER, Gizlene (1995). Op. Cit.

${ }^{21}$ Sobre o processo de fechamento da UDF, ver PENNA, Maria Luiza (2006). "A Experiência da UDF". In Luiz Camillo: perfil intelectual, Belo Horizonte: Editora UFMG.

${ }^{22}$ Para uma descrição resumida do que foi o projeto da UDF, bem como das principais personalidades envolvidas tanto na sua construção quanto no seu enfraquecimento e posterior fechamento, ver site do CPDOC/FGV. Ali também se encontra uma cópia do Decreto lei de transferência dos estabelecimentos de ensino da UDF para a Universidade do Brasil (http://cpdoc.fgv.br/producao/dossies/AEraVargas1/anos3037/RadicalizacaoPolitica/UniversidadeDistritoFederal).
} 
do belicismo, da disciplina, do autoritarismo e, quiçá, do totalitarismo. Defendemos, portanto, que analisar a cultura política germânica numa perspectiva relacional (Alemanha-Brasil) pode contribuir nesse esforço de resgate e reconhecimento de uma cultura que se distingue dos estereótipos;

B.) Dessa forma, queremos também compreender melhor o verdadeiro fascínio pela cultura alemã de um modo geral e, particularmente, pela sua cultura jurídica, especialmente no caso do Brasil.

C.) Por meio dessa perspectiva histórica relacional (Brasil-Alemanha) e transatlântica esperamos também contribuir para a um maior entendimento da própria constituição da cultura política brasileira, a partir de seus processos de seleção e recepção de ideias, apontando limites e possibilidades inovadoras (recalcadas, esquecidas dentro do vasto processo histórico).

D.) Para tanto, desejamos analisar a cultura política alemã no período de vai de 1879 a 1939, a partir dos processos de circulação, apropriação cultural e recepção das ideias de Rudolf von Jhering, Ernst Haeckel e Hans Kelsen na sua cultura política de "origem" - a germânica.

E.) Pretendemos descrever e interpretar os processos de circulação de ideias e apropriação cultural entre Brasil e Alemanha a partir dos autores germânicos mencionados e verificar a sua recepção no Brasil a partir dos autores brasileiros Clóvis Bevilaqua e Silvio Romero e das discussões em torno da Constituição brasileira de 1934. Estaremos atentos para as possíveis mediações culturais presentes nesse vasto processo, entre elas a da cultura ibérica e da francesa.

Nossa hipótese é a de que, ao mesmo que tempo em que ocorre a recepção de autores germânicos no Brasil, esse processo é sempre mediado pela influência de múltiplas culturas políticas, sendo a ibérica e a francesa as mais evidentes. Além disso, trabalhamos com a ideia de que há diferenças entre a forma como os referidos autores germânicos foram lidos e recepcionados, em suas respectivas culturas políticas; e a forma como estes foram lidos e apropriados dentro da cultura política brasileira. A conseqüência disso é um relativo desconhecimento da própria cultura política alemã e da inscrição dos referidos autores nesta. Assim, ao mesmo tempo em que ocorrem processos de circulação e apropriação de ideias, seguidos de um "reconhecimento" da cultura 
germânica e da formação de uma determinada visão do consiste a "germanidade" (Deutschtum), produz-se também outro efeito, típico dos referidos processos: o de "desconhecimento" 23 de outros aspectos da cultura germânica, que, em sua acomodação ficaram obscurecidos ou foram até mesmo ignorados, com ou sem intencionalidade. Produz-se, assim, uma idealização ${ }^{24}$ do significado da cultura germânica em geral e, em particular, do pensamento jurídico germânico.

Pensamos, ainda, que este trabalho servirá como suporte neste pequeno fragmento de pesquisa que estamos apresentando, a ideia trabalhada por Gisálio Cerqueira e Gizlene Neder, de que os autores alemães foram lidos no Brasil com sotaque francês $^{25}$. Ou seja, a recepção do pensamento alemão no Brasil teria sofrido forte mediação da cultura francesa, num percurso que passa também pelas influências da cultura ibérica.

Em suas pesquisas no acervo de Rui Barbosa, os professores Gisálio Cerqueira e Gizlene Neder observaram que o "Águia de Haia” aparentemente pouco lia em alemão, visto que na sua biblioteca não constam volumes em alemão, estando os autores germânicos presentes em traduções francesas, como é o caso das obras do iminente jurista alemão Von Savigny ${ }^{26}$. Essa hipótese reforça não apenas o peso da cultura francesa através de suas traduções do alemão, como também uma questão de legitimação intelectual no campo do direito: caso não se domine o idioma alemão, ao menos se deve aparentar dominá-lo. Este aspecto coloca outro indício da enorme idealização da cultura germânica, que até hoje persiste, particularmente no campo do direito. Outro "indício" ou "sintoma”, como diz o professor Gisálio Cerqueira, da força da cultura francesa é a forma como o nome do famoso jurista alemão é pronunciado correntemente em português: Von Savign-Y, com o acento do francês no "Y" final, em vez de Von S-A-vigny, com a ênfase da pronúncia alemã e seu acento no "A".

\footnotetext{
${ }^{23}$ Ver CERQUEIRA FILHO, Gisálio (1988). Análise Social da Ideologia, São Paulo: E.P.U. e CERQUEIRA FILHO, Gisálio (1982). A "Questão Social" no Brasil: crítica do discurso político, Rio de Janeiro: Civilização Brasileira, especialmente o capítulo 1, "Em torno de algumas questões teóricas e metodológicas", p. 21-53.

${ }^{24}$ Esta idealização está relacionada ao "paradigma da perfeição", estudado em suas relações com a ideia de mercado e de príncipe, respectivamente na economia política clássica e na teoria política moderna, na já aludida Dissertação de Mestrado intitulada "Tal Mercado tal Príncipe: o paradigma da perfeição na economia política burguesa", defendida em 31/03/2009, ICHF-PPGCP/UFF, Niterói.

${ }^{25}$ NEDER, Gizlene e CERQUEIRA FILHO, Gisálio (2007). Op. Cit.

${ }^{26}$ Ver NEDER, Gizlene e CERQUEIRA FILHO, Gisálio. "Os Filhos da Lei”. In: Ideias Jurídicas e Autoridade na Família. Op. Cit, p. 107-131.
} 
Esta hipótese se viu reforçada no caso dos autores que pesquisamos por uma afirmação de Tobias Barreto, que, ao apresentar o jurista Rudolf von Jhering, sublinha de maneira muito provocativa e bem ao seu gosto:

O leitor deve conhecê-lo [Rudolf von Jhering], se não por todas, por algumas de suas produções, pelo Geist des Römischen Rechts [Espírito do Direito Romano], pelo Kampf ums Recht [Luta pelo Direito], por exemplo, que se acham traduzidos em francês, ou, como eu já disse uma ocasião, reduzidos à clave de sol para o uso dos diletantes. ${ }^{27}$

\section{Acervos bibliográficos e alguns indícios de apropriação/tradução e recepção}

Os levantamentos preliminares de fonte bibliográfica para este trabalho foram realizados principalmente nos acervos da Biblioteca Nacional do Rio de Janeiro e do Tribunal de Justiça do Estado do Rio de Janeiro (TJRJ) ${ }^{28}$, devido a suas respectivas relevâncias para o campo jurídico. Em ambas foi possível encontrar o livro de Jhering L'Évolution Du Droit', assim como edições portuguesa ${ }^{30}$ e brasileira ${ }^{31}$ (esta última apenas na BN), ambas com o título "A Evolução do Direito", todas traduções da obra original de Jhering Zweck im Recht. Outro indício interessante é o fato do tradutor da edição francesa do livro L'Évolution Du Droit ser um certo Octave Louis Marie Ghislain de Meulenaere, tradutor da maior parte das obras de Jhering para o francês encontradas tanto na Biblioteca Nacional quanto na Biblioteca do TJRJ. Este é também o tradutor da versão mais antiga que encontrei do Código Civil Alemão de 1896 (de agosto de 1896 e que

\footnotetext{
${ }^{27}$ BARRETO, Tobias (2000). Estudos de Direito, Campinas: Bookseller, p. 81.

${ }^{28}$ Não posso deixar de agradecer a toda equipe de funcionários da Biblioteca do TJRJ que, através de sua simpatia e solicitude, tornaram meus momentos ali bastante agradáveis e em muito facilitaram meu trabalho de pesquisa.

${ }^{29}$ JHERING, Rudolf von (1901). L'Évolution Du Droit (zweck im recht), Paris: Chevalier Marescq et cie.

30 JHERING, Rudolf von (s/ data). A Evolução do Direito (zweck im recht), Lisboa: J. Bastos.

${ }^{31}$ JHERING, Rudolf von (1956). A Evolução do Direito (zwock im rocht), Salvador, Livraria Progresso.
} 
entrou em vigor em $1^{\circ}$ de jan. de 1900), datada de 1897, na Biblioteca do TJRJ ${ }^{32}$. O problema que coloco é o seguinte: A palavra alemã der Zweck não significa "evolução", mas "propósito", "fim" ou "finalidade"33.

Analisando mais detidamente as versões francesa e portuguesa de Zweck im Recht (traduzido como "Evolução do Direito") encontro no glossário o subtítulo "A missão do Direito"34 (Mission du Droitt ${ }^{35}$ ). "Missão": trata-se de palavra rara no vocabulário alemão, que nem possui vocábulo próprio de origem germânica, sendo utilizada a palavra de origem latina die Mission - a missão. Ao cotejar as duas traduções com a edição original da Biblioteca do $\mathrm{TJRJ}^{36}$, em alemão, descubro que a palavra "missão" é usada diversas vezes nesse trecho da obra" em tradução aos seguintes termos do alemão: Aufgabe (des Rechts) ${ }^{38}$ e Voraussetzung ${ }^{39}$. Aufgabe, no entanto, significa "tarefa", "dever" do direito (des Rechts) e Voraussetzung "pré-requisito", "pré-suposto". Não existe um vestígio sequer da palavra "missão" no original!

Além disso, a tradução apresenta alguns "erros" que suavizam o caráter contraditório do Direito, tal como este é apresentado por Jhering na versão original (notem que a palavra "contradição" é utilizada pelo próprio Jhering - do alemão der Widerspruch ${ }^{40}$ ). Apresento aqueles que considero os mais flagrantes, encontrados neste mesmo trecho da obra.

\footnotetext{
${ }^{32}$ Code Civil Allemand et loi d'introduction - traduits et annotés par O. de Meulenaere, Paris: ChevalierMarescq, 1897.

${ }^{33}$ Neste sentido a tradução em língua espanhola "El fin en el Derecho" de Leonardo Rodriguez (encontrada na BN) é mais fiel ao termo original alemão Zweck, assim como a tradução de Herder K. Hoffmann "A Finalidade do Direito", de 2002; JHERING, Rudolf von (s/ data). El fin en el Derecho (Zweck im recht), Madrid: B. Rodrguez Serra; JHERING, Rudolf von (2002). A Finalidade do Direito, Campinas: Bookseller.

34 JHERING, Rudolf von (s/ data). "Índice". Op. Cit., p. 385.

35 JHERING, Rudolf von (1901). "Table de Matières". Op. Cit., p. 386.

${ }^{36}$ JHERING, Rudolf von (1904). Der Zweck im Recht, Leipzig: Breitkopf und Hartel.

${ }^{37}$ Faço referência especificamente ao item 180., "Missão do Direito", no subcapítulo 12, "Fim do Direito. As Condições vitaes da sociedade", capítulo VIII, "A mecanica social ou os motores do movimento social" (JHERING, Rudolf von (s/ data). "180. Missão do Direito". Op. Cit., p. 290-293). Na edição francesa as referências são as seguintes: item 180, "Mission du droit", subcapítulo 12, "Le But Du Droit. - Les Conditions Vitales de la Société", Chapitre VIII, "La mécanique sociale ou les moteurs du mouvement social" (JHERING, Rudolf von (1901). "180. Mission du Droit". Op. Cit., p. 288-292.).

${ }_{38}$ JHERING, Rudolf von (1904). "Inhaltsverzeichnis". Op. Cit., p. XIX.

39 JHERING, Rudolf von (1904). "12) Der Zweck des Rechts - Die Lebensbedingungen der Gesellschaft". Op.Cit., p. 339.

${ }^{40}$ lbidem.
} 
a.) "Os dois elementos do direito, norma e coacção, que acabamos de analysar, são elementos de pura forma que nada nos ensinam do conteúdo do direito." $\rightarrow 11$ Tradução livre nossa: "Os dois momentos do direito desenvolvidos até agora, em sentido objetivo: a norma e a coação são momentos puramente formais que nada nos dizem sobre o conteúdo do direito." (Die beiden im bisherigen entwickelten Momente des Rechts im objektiven Sinne: die Norm und der Zwang sind rein formale Momente, die nichts über den Inhalt des Rechts aussagen ${ }^{42}$ )

b.) Há uma frase inteira que simplesmente foi deixada fora, que em tradução livre quer dizer ${ }^{43}$ : "A contradição, a mudança perpétua, parece ser a característica constitutiva do Direito" (Der Widerspruch, der ewige Wechsel scheint inhaltlich das Wesen des Rechts auszumachen $\left.{ }^{44}\right)$.

Fecho este trabalho com a seguinte indagação: Seguiremos lendo os pensadores alemães "em clave de sol para uso dos diletantes"45?

\section{Fontes e Bibliografia}

\section{Obras de Rudolf von Jhering:}

JHERING, Rudolf von (1901). L'Évolution Du Droit (zweck im recht), Paris: Chevalier Marescq et cie. (1904). Der Zweck im Recht, Leipzig: Breitkopf und Hartel.

(1955). Questões e Estudos de Direito; Tradução de João Vieira de Araujo, Clóvis Bevilaqua, Adherbal de Carvalho, Bahia: Livraria Progresso.

\footnotetext{
41 JHERING, Rudolf von (s/ data). Op. Cit., p. 289.

42 JHERING, Rudolf von (1904). Op. Cit., p. 339.

${ }^{43}$ Refiro-me ao já citado trecho "A Missão do Direito". O trecho cortado deveria constar na página 290 (JHERING, Rudolf von (s/ data). "180. Missão do Direito". Op. Cit., p. 290-293).

44 JHERING, Rudolf von (1904). Op. Cit., p. 339.

${ }^{45}$ BARRETO, Tobias (2000). Op. Cit., p. 81.
} 
(1956). A Evolução do Direito (zwock im rocht), Salvador, Livraria Progresso.

(2002). A Finalidade do Direito, Campinas: Bookseller.

(s/ data). A Evolução do Direito (zweck im recht), Lisboa: J. Bastos.

(s/ data). El fin en el Derecho (Zweck im recht), Madrid: B. Rodrguez Serra.

\section{Obras sobre Jhering:}

BARRETO, Tobias (2000). Estudos de Direito, Campinas: Bookseller.

\section{Códigos:}

Code Civil Allemand et loi d'introduction - traduits et annotés par O. de Meulenaere, Paris: Chevalier-Marescq, 1897.

\section{Decretos:}

Decreto-Lei de transferência dos estabelecimentos de ensino da Universidade do Distrito Federal para a Universidade do Brasil, 1939. Rio de Janeiro (RJ). (CPDOC/ GC 1936.09.18)

\section{Sítios da internet mencionados:}

http://cpdoc.fgv.br/producao/dossies/AEraVargas1/anos30-

37/RadicalizacaoPolitica/UniversidadeDistritoFederal

http://www.historia.uff.br/lcp/pesq.php

\section{Bibliografia:}

ALONSO, Ângela (2000). "Crítica e Contestação: o movimento reformista da geração de 1870". In Revista Brasileira de Ciências Sociais (RBCS), Vol. 15, no. 44, out., p. 35-55. 
BORRMANN, Ricardo G. Tal Mercado tal Príncipe: o paradigma da perfeição na economia política burguesa. Dissertação de Mestrado, Niterói: ICHF-PPGCP/UFF, 2009.

CERQUEIRA FILHO, Gisálio (1982). A "Questão Social” no Brasil: crítica do discurso político, Rio de Janeiro: Civilização Brasileira.

(1988). Análise Social da Ideologia, São Paulo: E.P.U.

CHARTIER, Roger (org.) (1996). Práticas da Leitura, São Paulo: Estação Liberdade.

FERRAZ JR., Tércio Sampaio (2000). "Por que ler Kelsen, Hoje". In COELHO, Fábio Ulhoa. Para entender Kelsen, São Paulo: Max Limonad, p. 13-20.

FREYRE, Gilberto (s/data, 2a ${ }^{-}$Ed.). 'Nós e a Europa Germânica' - Em torno de alguns aspectos das relações do Brasil com a cultura germânica no decorrer do século XIX, Rio de Janeiro: Editora Bra-Deutsch.

GINZBURG, Carlo (2002). Relações de força: história, retórica, prova, São Paulo: Companhia das Letras.

GRÜTZMANN, Imgart (2007). "Intelectuais de fala alemã no Brasil do século XIX: o caso de Karl von Koseritz (1830-1890)". In História Unisinos, Vol. 11, no. 1, Janeiro/Abril, p. 123-133.

MORAES FILHO, Evaristo de (1979). "O pensamento Político-Social de Silvio Romero". In ROMERO, Silvio. Realidades e ilusões no Brasil: Parlamentarismo e presidencialismo e outros ensaios, Petrópolis: Vozes: Aracajú: Governo do Estado de Sergipe.

NEDER, Gizlene (1995). “Juristas', 'Bacharéis' e a Ideia de Nação”. In Discurso Jurídico e Ordem Burguesa no Brasil, Porto Alegre: Sergio Antonio Fabris.

(2000). Iluminismo Jurídico-Penal Luso-Brasileiro: obediência e submissão, Rio de Janeiro: Freitas Bastos.

e CERQUEIRA Filho, Gisálio (2004). "A Teoria Política no Brasil \& o Brasil na Teoria Política". In $4^{\circ}$ Encontro da Associação Brasileira de Ciência Política (ABCP), 21-24 de julho, PUC-RJ.

e CERQUEIRA FILHO, Gisálio (2007). Ideias Jurídicas e Autoridade na Família, Rio de janeiro: Ed. REVAN.

e SILVA, Ana Paula Barcelos Ribeiro da (2009). "Intelectuais, Circulação de Ideias e Apropriação Cultural: Anotações para uma Discussão Metodológica". In Passagens. Revista Internacional de História Política e Cultura Jurídica, Rio de Janeiro: vol. 1 no. 1, janeiro/julho, p. 29-54. 
PAIM, Antônio (1966). A Filosofia da Escola do Recife. Rio de Janeiro: Editora Saga.

PENNA, Maria Luiza (2006). "A Experiência da UDF". In Luiz Camillo: perfil intelectual, Belo Horizonte: Editora UFMG.

PRUTSCH, Ursula (1999). "Instrumentalisierung deutschsprachiger Wissenschafter zur Modernisierung Brasiliens in den dreißiger und vierziger Jahren". In Zeitgeschichte.at, Innsbruck: Studienverlag, p. 362-69.

VILLAÇA, Antônio Carlos (1975). O Pensamento Católico no Brasil, Rio de Janeiro: Zahar Editores.

Recebido para publicação em junho de 2011. 